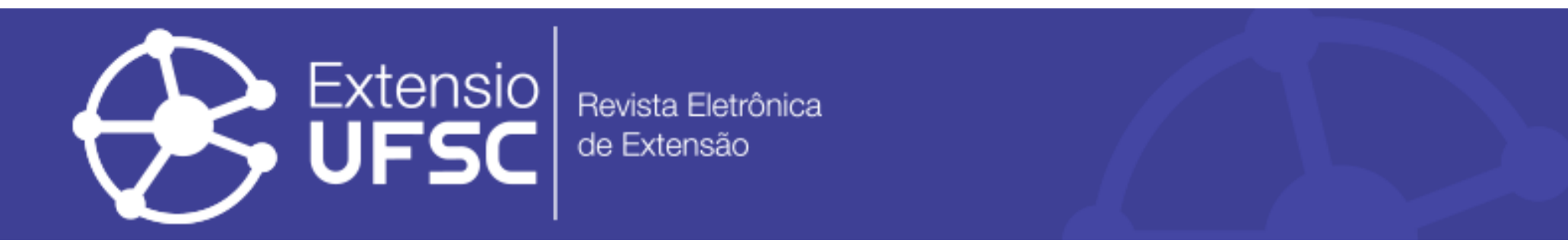

\title{
DIAGNÓSTICO SOCIOECONÔMICO DE PECUARISTAS FAMILIARES DE SÃO FRANCISCO DE PAULA
}

\author{
Jean Carlos Matos \\ SICREDI Pioneira \\ jean.carlos.matos@gmail.com
}

Miguelangelo Ziegler Arboitte

Instituto Federal Catarinense

miguelangelo.arboitte@ifc.edu.br

\begin{abstract}
Resumo
Em São Francisco de Paula (RS), o pecuarista familiar é importante categoria social, tradicional na produção de bovinos de corte a base de campo nativo, produzindo carne e leite desses animais. Esses produtores estão em vulnerabilidade social, pela baixa tecnologia empregada nas propriedades e pouco acesso a políticas públicas, resultando em baixos índices econômicos e zootécnicos, sendo público prioritário da extensão rural promovida pela EMATER/RS - ASCAR. O trabalho foi realizado no período de janeiro a marco de 2018, através de amostragem dos pecuaristas familiares, com o objetivo de traçar o perfil socioeconômico. O tamanho médio das propriedades é de 80,41 ha, sendo 66,63\% da área composta por campo nativo, com padrão racial dos bovinos oriundos dos cruzamentos entre raças zebuínas e europeias, com aptidão para leite e carne. As principais fontes de renda verificadas são o queijo artesanal serrano, a venda de bezerros e vacas e a aposentadoria rural.
\end{abstract}

Palavras-chave: Bovinos de Corte. Bovinos de Leite. Pecuária Familiar. Queijo Artesanal Serrano. Sustentabilidade.

\section{SOCIOECONOMIC DIAGNOSIS OF FAMILY FARMS OF SÃO FRANCISCO DE PAULA}

\begin{abstract}
In São Francisco de Paula, RS, the family farmer is an important social category, traditional in the production of beef cattle, based on the native field, producing meat and milk of these animals. These producers are in social vulnerability, due to the low technology used in the properties and the lack of access to public policies, resulting in low economic and zootechnical indexes, is a priority public of the rural extension promoted by EMATER / RS - ASCAR. This work was carried out in the period from January to March 2018, through the sampling of the family ranchers, as the objective of tracing the socioeconomic profile. The average size of the farms was 80.41 ha, with $66.63 \%$ of the area comprising the native field, with a bovine breed pattern of crossbreeding between Zebu and European breeds, with milk and meat fitness. The main sources of income verified were artisan cheese, the sale of calves and cows and rural retirement.

Keywords: Beef Cattle Cutting. Dairy Cattle. Family Farming. Serrano Artisanal Cheese. Sustainability.

\section{DIAGNÓSTICO SOCIOECONÓMICO DE GANADEROS FAMILIARES DE SÃO FRANCISCO DE PAULA}

\section{Resumen}

En São Francisco de Paula, el ganadero familiar es importante categoría social, tradicional en la producción de bovinos de corte a base de campo nativo, produciendo carne y leche de esos animales. Estos productores están en vulnerabilidad social, por la baja tecnología empleada en las propiedades y el poco acceso a políticas públicas, resultando en bajos índices económicos y zootécnicos, es público prioritario de la extensión rural promovida por EMATER / RS - ASCAR. Este trabajo fue realizado en el período de enero a marzo de 2018, a través de muestreo de los ganaderos familiares, como el objetivo de trazar el perfil socioeconómico. El tamaño promedio de las propiedades fue de 80,41 ha, siendo 66,63\% del área compuesta por campo nativo, con patrón racial de los bovinos oriundos de los cruces entre razas cebuinas y europeas, con aptitud para leche y carne. Las principales fuentes de ingresos verificadas fueron el queso artesanal serrano, la venta de becerros y vacas y la jubilación rural.

Palavras clave: Bovinos de Corte. Bovinos de Leche. Pecuaria Familiar. Queso Artesanal Serrano. Sostenibilidad. 


\section{INTRODUÇÃO}

A agropecuária da região dos Campos de Cima da Serra/RS passa por transição, com avanço da agricultura e silvicultura em áreas onde era predominante a bovinocultura de corte, porém a pecuária continua sendo a base sólida da economia regional. Existindo diferentes níveis de tecnologias, a bovinocultura de corte e a leiteira utilizam o campo nativo como base de alimento para os animais.

O município de São Francisco de Paula está inserido nos Campos de Cima da Serra, a 945 metros ao nível do mar, com extensão de $3.274 \mathrm{~km}^{2}$, localizada no nordeste do Estado do Rio Grande do Sul, a $112 \mathrm{~km}$ da capital gaúcha, Porto Alegre. Apresenta uma população total de 20.537 pessoas, sendo 7.533 moradoras em área rural (IBGE, 2010), e desses, mais de 1.000 famílias são pecuaristas familiares (EMATER/RS-ASCAR, 2017).

A origem do povo dos Campos de Cima da Serra, cujo gentílico denomina-se Serrano, é predominante de origem portuguesa, com alguns traços de origem alemã e italiana. A região também foi fortemente influenciada pelas rotas dos tropeiros que ligavam os Campos de Cima da Serra a São Paulo. A cultura do gaúcho serrano é nítida no modo de viver das pessoas, muito apegadas à pecuária bovina e equina.

As propriedades rurais na sua maioria $(78,75 \%)$ estão inseridas em área não superior a 100 ha, ocupando 29,42\% da área do município (IBGE, 2010). Caracterizam-se como áreas de pecuária familiar, baseada na produção extensiva, caracterizada pela manutenção do meio ambiente com mínimas alterações, utilizando-o de forma pouco agressiva e pouco dependente de insumos externos.

Reconhecendo a importância econômica e social deste segmento, foi instituído no Estado do Rio Grande do Sul pela Lei Estadual no 13.515, de 13 de setembro de 2010, o Programa Estadual de Desenvolvimento da Pecuária de Corte Familiar, que tornou o apoio a esses produtores política de Estado. Após a regulamentação desta lei, o artigo $3^{\circ}$ fez a definição do que é o pecuarista familiar:

Tenham como atividade predominante a cria ou a recria de bovinos e/ou caprinos e/ou bubalinos e/ou ovinos com a finalidade de corte;

Utilizem na produção trabalho predominantemente familiar, podendo utilizar mão de obra contratada em até cento e vinte dias ao ano;

Detenham a posse, a qualquer título, de estabelecimento rural com área total, contínua ou não, inferior a trezentos hectares;

Tenham residência no próprio estabelecimento ou em local próximo a ele; e

Obtenham no mínimo setenta por cento da sua renda provinda da atividade pecuária e não agropecuária do estabelecimento, excluídos os benefícios sociais e os proventos previdenciários decorrentes de atividades rurais. Estado do Rio Grande do Sul (2010). 
Para Waquil et al. (2016) a Lei Estadual n 13.515, de 13 de setembro de 2010, permitiu algum destaque a esta categoria social, a qual mantém mão de obra familiar de forma predominante, usa da criação de bovinos de corte e ovinos como principal fonte de renda e depende do meio ambiente sem modificações de médio e grande porte para sustentar sua propriedade, destacando ainda três aspectos em relação aos estudos realizados sobre a pecuária familiar no Rio Grande do Sul:

\footnotetext{
A desmistificação da ideia de que a produção pecuária era realizada por grandes produtores, onde $70 \%$ do total dos empreendimentos rurais dedicados a atividade da pecuária de corte, são oriundos de pecuaristas familiares (60 mil famílias).

Que mesmo envolvendo a criação de animais, a pecuária familiar apresenta boa diversidade no contexto socioeconômico, produtivo e ambiental.

Esta diversidade está no modo de vida e estratégias utilizadas para conduzir suas propriedades, como a particularidade dos Campos de Cima da Serra envolvendo queijo artesanal serrano. E o terceiro aspecto, foi a união dos interessados em representações sociais, que acessaram políticas públicas com algumas restrições.
}

Através do Programa Estadual de Desenvolvimento da Pecuária de Corte Familiar, permitiu-se que o pecuarista familiar acessasse linhas de financiamento e viabilizou-se aplicação de melhorias em suas propriedades. Para que programas como este sejam aplicados, é necessário embasamento de estudos ligados ao conhecimento social, que possam melhor compreender os anseios daquele público alvo, indo a fundo em todos os caminhos do pensamento, seja o econômico ou o de bem-estar.

Apesar de existirem publicações envolvendo o pecuarista familiar, os estudos regionalizados são voltados à região da Campanha do Rio Grande do Sul, existindo particularidades que envolvem a diversificação e o modo de vida destes em relação ao seu contexto. Este estudo tem como proposta enriquecer o conhecimento sobre o pecuarista familiar no Estado do Rio Grande do Sul, utilizando como objeto de estudo o município de São Francisco de Paula, onde algumas particularidades salientarão a importância e a tradição deste extrato da população rural.

Como objetivos este trabalho busca obter respostas sobre os principais gargalos da pecuária extensiva executada pelos pecuaristas familiares no município; traçar perfil do pecuarista familiar no município de São Francisco de Paula; disponibilizar estes dados como ferramenta de políticas públicas para o município.

\section{MATERIAIS E MÉTODOS}

O município de São Francisco de Paula, onde foi realizada a pesquisa, tem longa tradição na pecuária, que se iniciou na época da colonização. Dos 7.533 habitantes (IBGE, 2010) que são considerados população rural, mais de 1.000 famílias são pecuaristas familiares (EMATER/RS- 
ASCAR, 2017). Além da importância numérica, o trabalho com este público vem sendo executado pela instituição como prioritário para desenvolvimento rural.

De acordo com informações da Inspetoria Veterinária de São Francisco de Paula, no ano de 2016 o rebanho bovino do município era de 134.265 cabeças, com cerca de 42\% (56.820) do rebanho composto por fêmeas de mais de 36 meses, o que mostra a aptidão da região para cria.

\begin{tabular}{|l|c|c|c|}
\hline Idade em meses & Macho & Fêmea & Total \\
\hline $0-12$ meses & 12.177 & 13.292 & 25.469 \\
\hline 13-24 meses & 10.579 & 12.236 & 22.815 \\
\hline 25-36 meses & 8.267 & 12.147 & 20.414 \\
\hline Acima de 36 meses & 8.747 & 56.820 & 65.567 \\
\hline Total & $\mathbf{3 9 . 7 7 0}$ & $\mathbf{9 4 . 4 9 5}$ & $\mathbf{1 3 4 . 2 6 5}$ \\
\hline
\end{tabular}
Fonte: Inspetoria Veterinária de São Francisco de Paula (2016).

Uma vez delimitada a área total do município como foco do estudo, a forma de questionário semiestruturado foi aplicada conforme metodologias de Cotrim (2003), Ribeiro (2003) e de Ambrosini, Miguel e Filippi (2009).

O questionário foi fundamentado em análise socioeconômica, proposta por Búrigo, Cazzela e Rover (2015), em que o resultado esperado era o diagnóstico de como a propriedade dos pecuaristas familiares está inserida no contexto produtivo, qual sua capacidade de trabalho e gargalos para possível intervenção da extensão rural (Anexo 1).

Os questionários semiestruturados foram aplicados de forma aleatória a 36 pecuaristas familiares que aceitarem a participação na pesquisa e responderam de forma espontânea, escolhidos do total dos 328 assistidos pela EMATER/RS - ASCAR de São Francisco de Paula.

Para o cálculo do tamanho da amostra, foi utilizada a metodologia proposta por Gil (1999), para o caso de populações finitas.

$$
n=\frac{\sigma^{2} \cdot p \cdot q \cdot N}{e^{2}(N-1)+\sigma^{2} \cdot p \cdot q}
$$

Onde: $\mathrm{N}=$ tamanho da amostra;

$\sigma^{2}=$ intervalo de confiança escolhido, expresso em números de desvio;

$\mathrm{p}=$ porcentagem com o qual o fenômeno se verifica, estimado;

$\mathrm{q}=$ porcentagem complementar $(100-\mathrm{p})$;

$\mathrm{N}=$ tamanho da população;

$\mathrm{e}^{2}=$ erro máximo permitido. 
A análise dos resultados foi realizada de forma similar à utilizada por Porto e Bezerra (2009), através de análise de clusters ou conglomerados, que objetiva agrupar os indivíduos (casos) que possuem características semelhantes em função de um conjunto de variáveis selecionadas. Estes conglomerados serão grupos homogêneos, os quais demonstrarão as variações dentro do público-alvo da pesquisa.

Os questionários foram aplicados em eventos organizados pela EMATER/RS - ASCAR, com produtores rurais que se enquadram como público-alvo da pesquisa no período de 02/01/2018 a 30/03/2018.

Foi acordado com os entrevistados que quaisquer informações pessoais não seriam divulgadas, muito menos atrelado aos resultados a identificação deles. Todos os resultados foram discutidos de forma anônima e imparcial.

Os resultados obtidos foram agrupados na mesma sequência de aplicação das perguntas, formando então oito grupos distintos, sendo estes: 5.1 - identificação do estabelecimento; 5.2 composição da família e disponibilidade de mão de obra; 5.3 - ocupação da área; 5.4 - instalações disponíveis; 5.5 - máquinas e implementos disponíveis; 5.6 - rebanho bovino e seu manejo; 5.7 composição percentual da renda da propriedade (no último ano); 5.8 - principais dificuldades identificadas pela família.

O que foi contado como entrevistado foi o titular ou chefe da família, mas que em muitos dos entrevistados contava com o segundo titular junto consigo no momento da aplicação do mesmo. As repostas foram baseadas no consenso dos mesmos. O foco foi na unidade familiar como um todo.

Foi permitido também, em caso de dúvida ou preferência não responder a pergunta, garantindo este direito aos entrevistados.

\section{RESULTADOS E ANÁLISES}

A condição de posse das propriedades é um fator muito importante, pois em áreas próprias, em tese, os investimentos fixos são mais pertinentes, como construção de sede, centrais de manejo, divisões de área entre outros. Porém, em outras situações os pecuaristas familiares possuem apenas arrendamento, que além de ter custos é por tempo limitado, dificultando ou até impedindo investimentos que trariam melhorias para aquela área. 


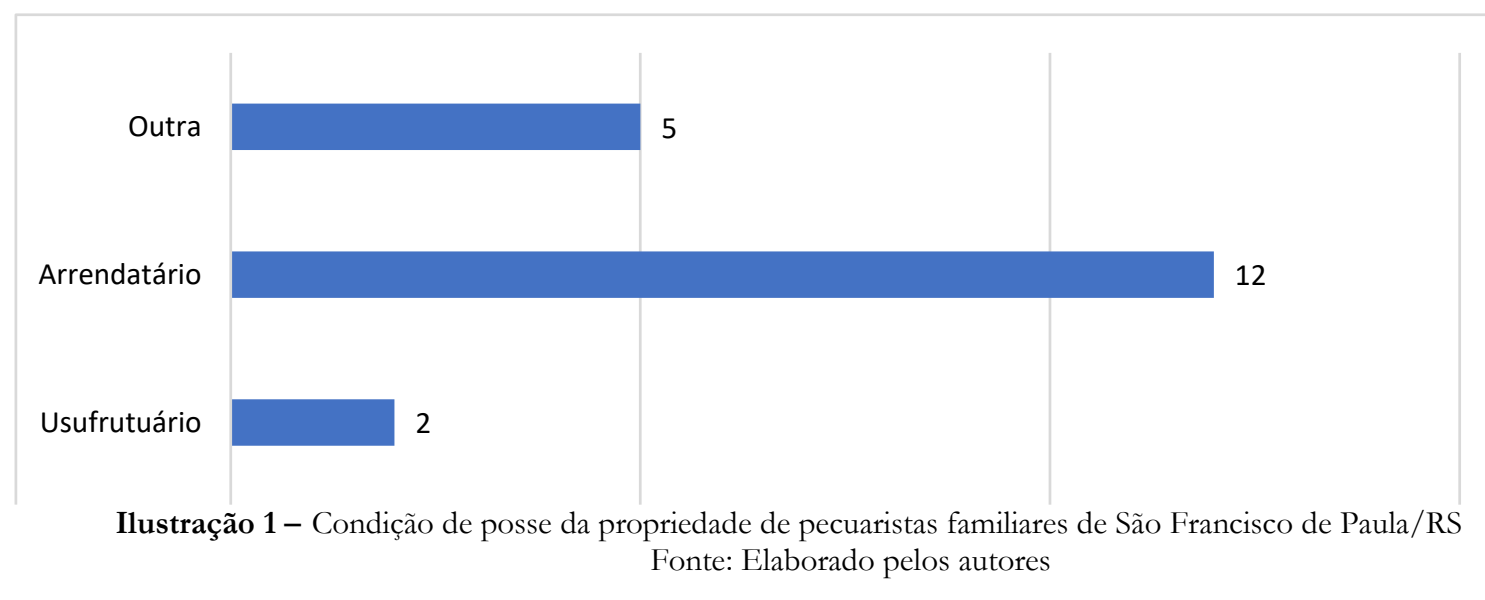

O número de amostras representadas na Ilustração 1, foi de 41, superior ao número amostral pré-determinado que era de 36, por que alguns produtores além de proprietários, arrendam áreas ou são usufrutuários de outras áreas. Da amostragem realizada, 22 responderam que são proprietários, dentre estes três também arrendam áreas. Também há um caso de proprietário que também é usufrutuário de mais uma parcela de área.

O principal motivo de se arrendar área é aumentar sua capacidade produtiva. As áreas arrendadas podem ser de parentes, parceiros agrícolas ou terceiros sem interesse de uso das áreas. O arrendamento representou 12 famílias de pecuaristas familiares, e o usufruto, duas famílias. O valor utilizado para o arrendamento de terras na região é baseado no peso do boi gordo, sendo utilizada a sistemática de $1.000 \mathrm{~kg}$ para cada 45 ha.

A condição de posse da terra relatada na Ilustração 1 como "Outra" engloba as áreas utilizadas em comodato, cedência ou posse.

Para composição da família, foi considerado como integrante aqueles que atuam na propriedade, auxiliando no cotidiano dos afazeres, mesmo não residindo na mesma.

Os chefes das famílias foram os entrevistados pelo questionário, destes, 94\% eram homens e apenas 6\% eram mulheres (Ilustração 2). Porém, os homens que responderam que eram os chefes da família, em muitos casos quando possível estes estavam acompanhados de seus cônjuges para auxílio e qualificação das respostas, demonstrando que de certa forma há uma divisão das responsabilidades de controle das ações quando se trata de pecuária familiar. 


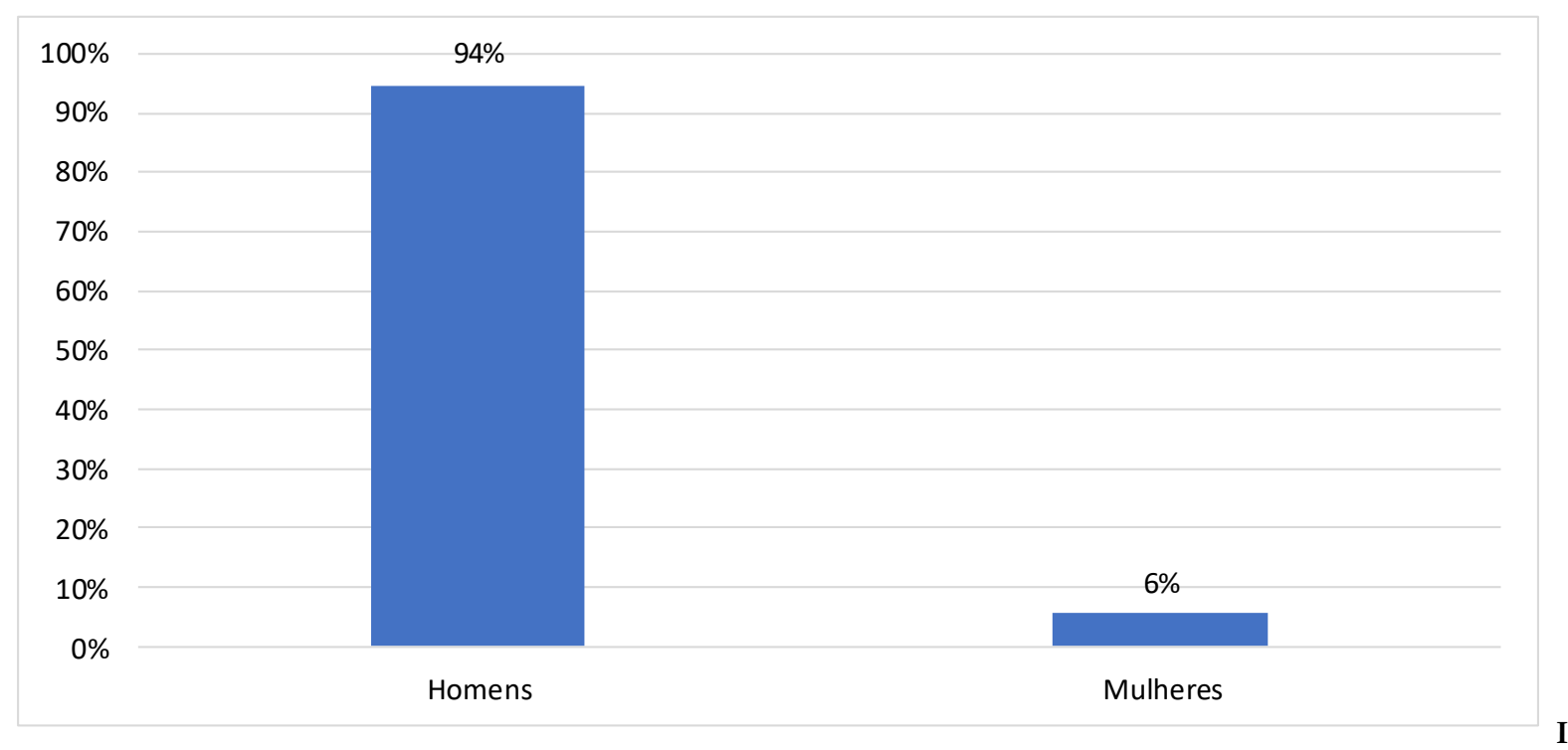

lustração 2- Sexo dos chefes de família de pecuaristas familiares de São Francisco de Paula/RS.

Fonte: Elaborado pelos autores

Fica evidenciado na Ilustração 2 a masculinização nas propriedades de pecuária familiar, onde os homens representam 57\% dos componentes.

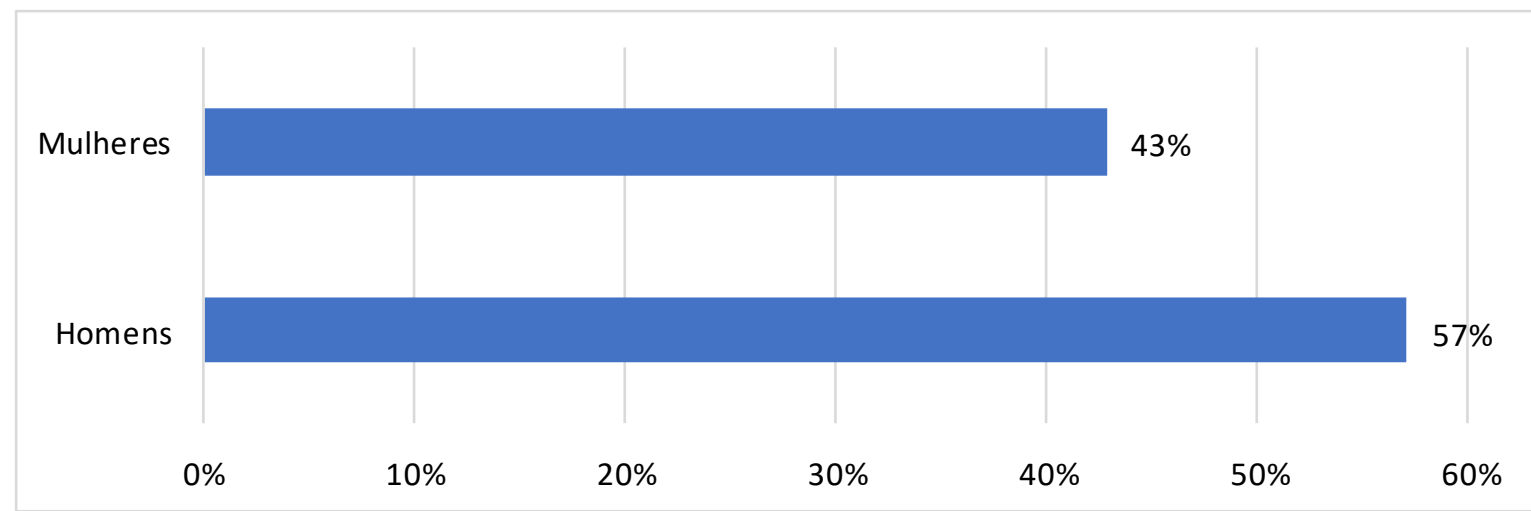

Ilustração 3- Composição por sexo da família de pecuaristas familiares de São Francisco de Paula/RS Fonte: Elaborado pelos autores

Outro fator constatado é o nítido envelhecimento dos componentes familiares (Quadro 2), em que das famílias entrevistadas, 48,4 \% têm idade superior a 50 anos, dado preocupante que tem levado à escassez de mão-de-obra, e por se tratar de atividade muitas vezes insalubre, acelera problemas naturais decorrentes da idade. 


\begin{tabular}{|c|c|c|}
\hline Faixa de idade (anos) & Quantidade de indivíduos & Porcentagem (\%) \\
\hline Até 19 & 16 & $17,6 \%$ \\
\hline De 20 a 29 & 9 & $9,9 \%$ \\
\hline De 30 a 39 & 13 & $14,3 \%$ \\
\hline De 40 a 49 & 9 & $9,9 \%$ \\
\hline De 50 a 59 & 16 & $17,6 \%$ \\
\hline De 60 a 69 & 17 & $18,7 \%$ \\
\hline Acima de 70 & 11 & $12,1 \%$ \\
\hline Total & 91 & $100 \%$ \\
\hline
\end{tabular}

Quadro 2 - Faixa etária da família dos pecuaristas familiares de São Francisco de Paula/RS.

Fonte: Elaborado pelos autores

Para este levantamento da ocupação da área, não foi utilizado instrumentos de medição, mas apenas o conhecimento do entrevistado em relação à sua propriedade.

Algo a ser considerado na realidade regional são as limitações de uso da terra por conta do relevo, como afloramento de rochas e condições naturais de baixa fertilidade de solo, como o citado por Porto e Bezerra (2009) que são características semelhantes para municípios com atividade predominante em pecuária de corte.

\begin{tabular}{|c|c|c|c|}
\hline Estratos de área (ha) & Frequência & Porcentagem (\%) & Porcentagem acumulada (\%) \\
\hline $0-50$ & 13 & 36 & 36 \\
\hline $51-100$ & 15 & 42 & 78 \\
\hline $101-200$ & 6 & 17 & 100 \\
\hline $201-300$ & 2 & 6 & \\
\hline Total & 36 & 100 & \\
\hline
\end{tabular}

Quadro 3 - Distribuição dos estratos da área total dos estabelecimentos rurais de pecuaristas familiares de São Francisco de Paula/RS.

Fonte: Elaborado pelos autores

Os resultados de Porto e Bezerra (2009) no município de Bagé/RS demonstraram que $80 \%$ das propriedades contempladas na pesquisa são menores do que 200 ha, sendo que no presente trabalho esta porcentagem foi de $94 \%$. Isto evidencia a realidade da pecuária familiar tanto em Bagé como em São Francisco de Paula, em áreas que, para a atividade de pecuária de corte, são consideradas pequenas áreas pois esta impõe algumas dificuldades produtivas e 
mercadológicas, como por exemplo a formação um lote uniforme de terneiros com mais de 50 animais.

A área média das propriedades foi de 80,41 ha, a qual no município de São Francisco de Paula conforme Lei $n^{\circ} 11.326$ (Programa Nacional de Fortalecimento da Agricultura Familiar) ainda se enquadra como agricultor familiar, na qual a regra permite até quatro módulos fiscais, que são de 25 ha cada. Oito dos entrevistados possuem área superior aos 100 ha citados para enquadramento como agricultor familiar, os outros 28 possuem áreas inferiores a 100 ha.

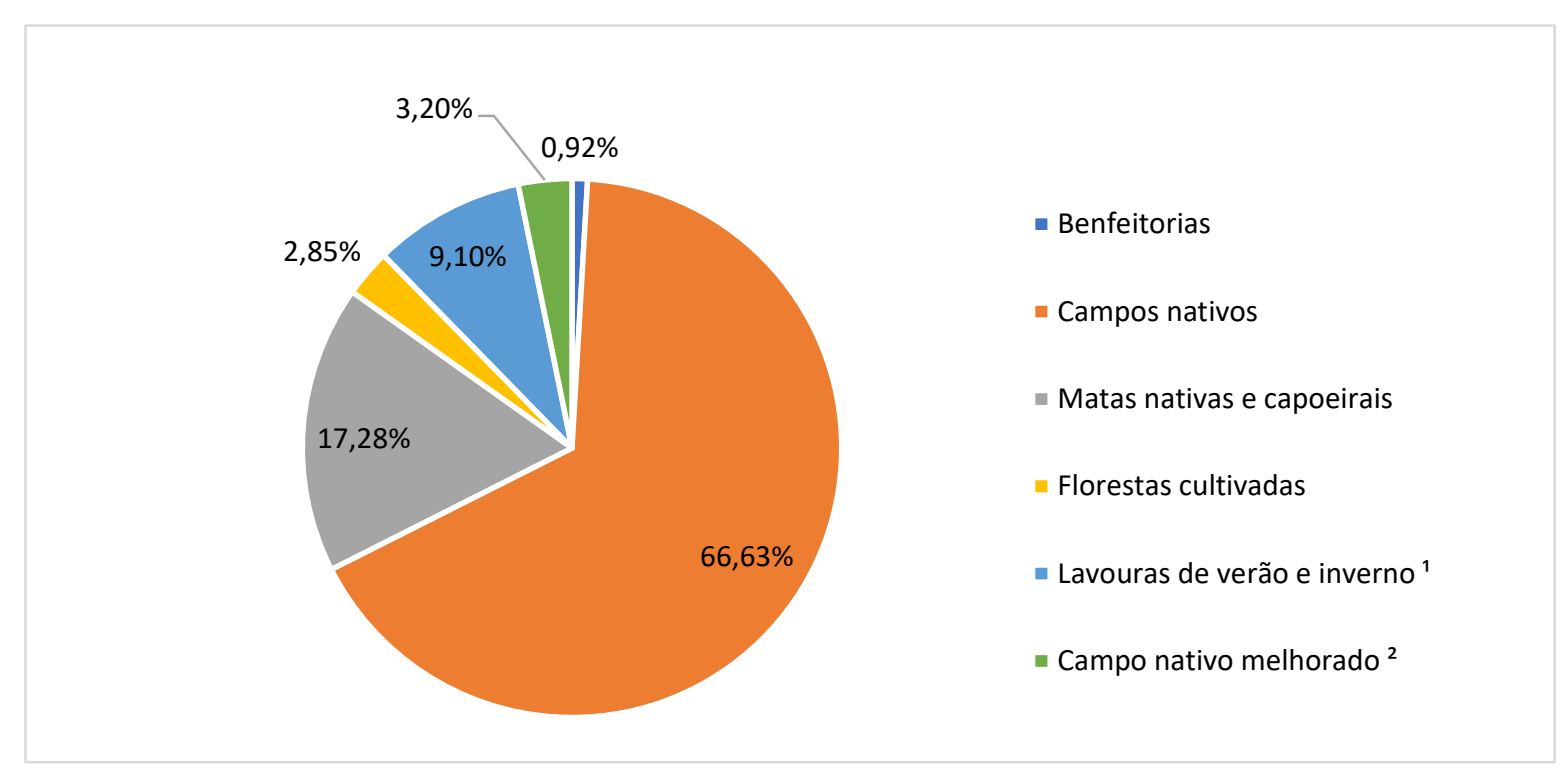

Ilustração 4- Estratificação da área das propriedades de pecuaristas familiares de São Francisco de Paula/RS Fonte: Elaborado pelos autores

$\mathrm{Na}$ Ilustração 4 as Lavouras de verão e inverno ${ }^{1}$ são áreas de plantios anuais ou perenes de forrageiras ou de grãos, enquanto o Campo nativo melhorado ${ }^{2}$ se refere a campos que passaram por melhorias, seja em manejo (ajustes de carga animal adequando essas à pressão de pastejo), correção de solo (calcário) ou introdução de espécies forrageiras principalmente a de ciclo invernal.

Ries, Luz e Araújo (2012) obtiveram dados semelhantes aos da Ilustração 4, em que $57,3 \%$ da área total é coberta por campos nativos e 19,1\% por matas nativas e capoeirais. Em contrapartida, os dados obtidos pelo autor (Ilustração 4) foram de 66,63\% da área coberta com campos nativos e 17,28\% de cobertura por matas nativas e capoeirais. A área pastagens cultivadas, seja na forma de campos nativos melhorados ou de lavouras somada atinge 13,7\%, contra 12,3\% obtidos por Ries, Luz e Araújo (2012).

Como demonstrado na Ilustração 4, a ocupação predominante da área é por campos nativos, que são a base de alimentação dos rebanhos. Tanto as áreas transformadas em lavouras quanto as transformadas em campo nativo melhorado têm por objetivo melhorar a alimentação 
dos animais, sendo que 34 dos entrevistados utilizam aveia preta (Avena strigosa Schreb.), aveia branca (Avena sativa L.), azevéns (Lolium multiflorum Lam.), trevo-branco (Trifolium repens L.) e trevo vermelho (Trifolium pratense L.) em suas áreas. Estas espécies complementam a alimentação dos animais em períodos de escassez de forragem e qualificam a dieta.

Como culturas não relacionadas à produção de forragem, foi citado o milho para produção de grãos e silagem, além de feijão e moranga para comercialização.

\begin{tabular}{|c|c|c|}
\hline Valores & Campo nativo & Pastagem cultivada \\
\hline Mínimo & 1 & 1 \\
\hline Máximo & 8 & 22 \\
\hline Média & 2,2 & 5,3 \\
\hline
\end{tabular}

Quadro 4 - Número de divisões utilizados para manejo do campo nativo e áreas de pastagem cultivada de pecuaristas familiares de São Francisco de Paula/RS

Fonte: Elaborado pelos autores

Foi constatado no Quadro 4 o baixo número de divisões nas áreas de campo nativo (2,2 em média), o qual é manejado de forma extensiva durante todo o ano. Já nas áreas de pastagem cultivada esta realidade foi diferente, com uma média de 5,3 divisões por propriedade.

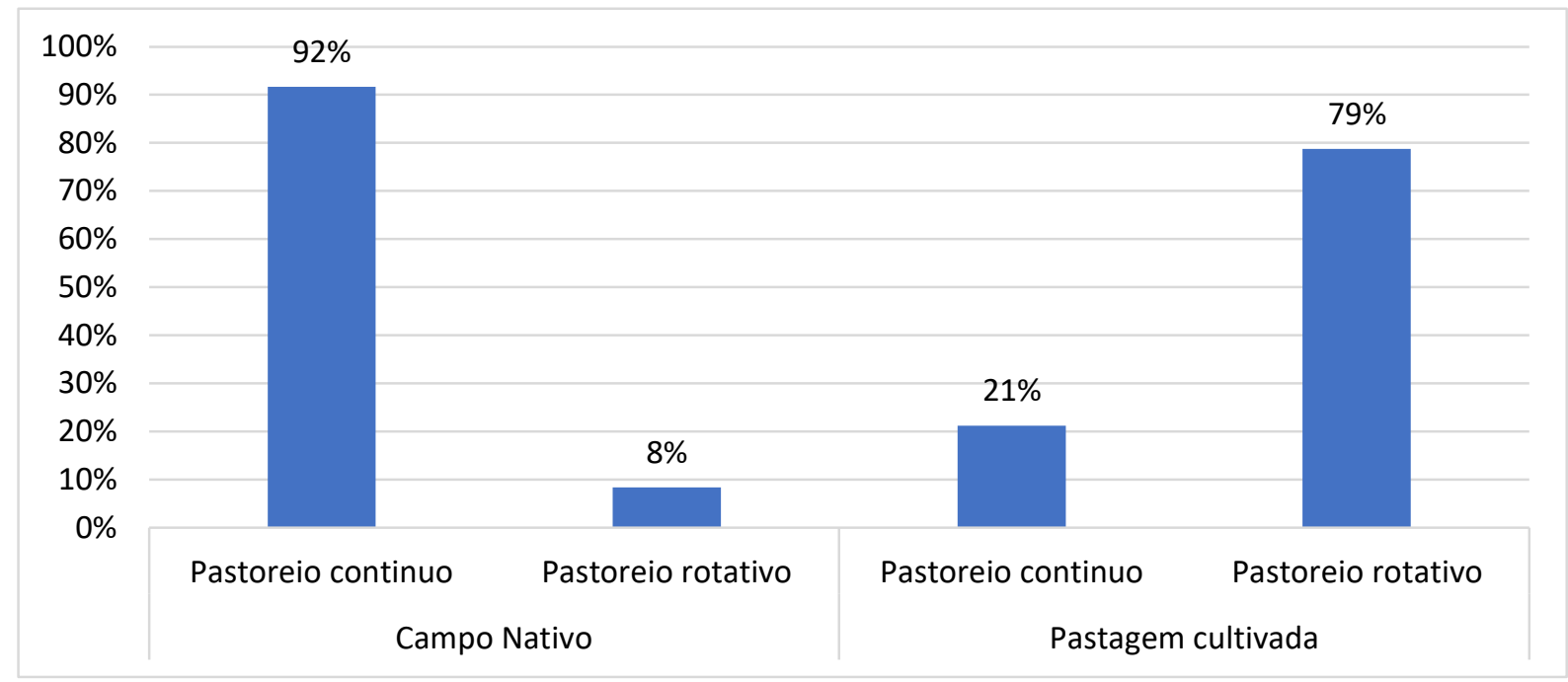

Ilustração 5- Tipo de pastoreio utilizado por pecuaristas familiares de São Francisco de Paula/RS

Fonte: Elaborado pelos autores

$\mathrm{Na}$ Ilustração 5 distingue-sem os manejos de campo nativo e pastagem cultivada. Em campo nativo é predominante a utilização de pastoreio contínuo, relatado por $92 \%$ dos pecuaristas familiares. Já em pastagem cultivada, seu manejo predominante é o pastoreio rotativo, relatado por $79 \%$ dos entrevistados.

Um fator importante a ser citado também em relação à Tabela 2, principalmente em relação às divisões em campo nativo, é o fato das sapecas ou queimadas de campo, o que 
degradam bastante as cercas ou demandam mão de obra para construção de aceiros para não serem atingidas.

$\mathrm{Na}$ aplicação dos questionários, também procurou-se entender quais as atuais condições de trabalho em relação a instalações e benfeitorias nas propriedades. Estas dão autonomia e diminuem a penosidade dos trabalhadores quando mantidas em boas condições.

\begin{tabular}{|l|c|c|c|c|c|}
\hline Estado Benfeitoria & Ruim & Regular & Bom & Total & Não possui \\
\hline Galpão & 5 & 7 & 21 & 33 & 3 \\
\hline Mangueira & 3 & 6 & 18 & 27 & 9 \\
\hline Cerca fixa & 2 & 16 & 18 & 36 & 0 \\
\hline Brete & 3 & 2 & 22 & 27 & 9 \\
\hline Balança & 0 & 0 & 9 & 9 & 27 \\
\hline Cerca elétrica & 0 & 0 & 21 & 21 & 15 \\
\hline Total & $\mathbf{1 3}$ & $\mathbf{3 1}$ & $\mathbf{1 0 9}$ & $\mathbf{1 5 3}$ & $\mathbf{6 3}$ \\
\hline Porcentagem (\%) & $\mathbf{8}$ & $\mathbf{2 0}$ & $\mathbf{7 1}$ & $\mathbf{1 0 0}$ & - \\
\hline
\end{tabular}

Quadro 5 - Instalações e benfeitorias disponíveis e suas atuais condições para os pecuaristas familiares de São Francisco de Paula/RS

Fonte: Elaborado pelos autores

Outras benfeitorias citadas, todas em boas condições, foram um carregador de bovinos e dois banheiros de imersão, sendo um destes desativado.

Foi predominante nas entrevistas (Quadro 5) o relato de que as instalações estavam em boas condições (71\%). O item citado mais vezes como ruim foi o galpão e o item mais citado como regular, foi a cerca fixa. Como relatado anteriormente, as cercas de um modo geral são castigadas pelas sapecas de campo nativo, sendo conduzida pelos proprietários lindeiros.

Algo característico na região, em geral, é o compartilhamento de instalações como mangueiras e bretes para o manejo dos bovinos. Variando de periodicidade, os produtores precisam manejar os animais em locais centralizados para realizar vacinação obrigatória pela Secretaria da Agricultura, Pecuária e Irrigação do Rio Grande do Sul (SEAPI/RS) contra brucelose e febre-aftosa, como também outras vacinas contra leptospirose e carbúnculo, além do controle de ecto e endoparasitas.

Máquinas e implementos agrícolas em propriedades de pecuária são necessários não para o manejo direto dos animais, mas para facilitar serviços como plantio de forrageiras, grãos, transporte em geral e manejo das pastagens (roçadas por exemplo). 


\begin{tabular}{|l|c|c|c|c|c|}
\hline Estado Máquinas/Equipamentos & Ruim & Regular & Bom & Total & Não possui \\
\hline Trator & 1 & 4 & 2 & 7 & 19 \\
\hline Arado & 1 & 2 & 4 & 7 & 29 \\
\hline Roçadeira & 0 & 0 & 14 & 14 & 22 \\
\hline Semeadora & 0 & 0 & 11 & 11 & 25 \\
\hline Total & 2 & 6 & 41 & 49 & 95 \\
\hline Porcentagem (\%) & 4 & 12 & 84 & 100 & - \\
\hline
\end{tabular}

Quadro 6 - Máquinas e implementos disponíveis e suas atuais condições para os pecuaristas familiares de São Francisco de Paula/RS

Fonte: Elaborado pelos autores

Cerca de 44\% dos entrevistados não possuem nenhuma das máquinas e implementos citados acima. Estes utilizam equipamentos de forma contratada ou em forma associativa, com maquinário cedido pela prefeitura municipal de São Francisco de Paula.

Outras máquinas e implementos citados pelos produtores foram carreta agrícola, roçadeira costal, grade niveladora, escarificador, motosserra, resfriador de leite, plataforma traseira e enxada rotativa.

Importantes também na diminuição da penosidade do trabalho, as máquinas e implementos agrícolas próprios dão autonomia às propriedades. Porém há um alto custo a ser imobilizado ao adquiri-los. O uso de financiamentos é comum também entre pecuaristas familiares para a aquisição de tratores, grades, semeadoras entre outros.

Como já citado anteriormente e reforçado pela Ilustração 6, a principal aptidão dos rebanhos de pecuaristas familiares é a cria, em que segundo os entrevistados totaliza mais de $50 \%$ do rebanho (considerando fêmeas acima de 36 meses). Além da produção do bezerro, este rebanho de matrizes adultas é por muitas vezes ordenhado para a confecção do queijo artesanal serrano. 


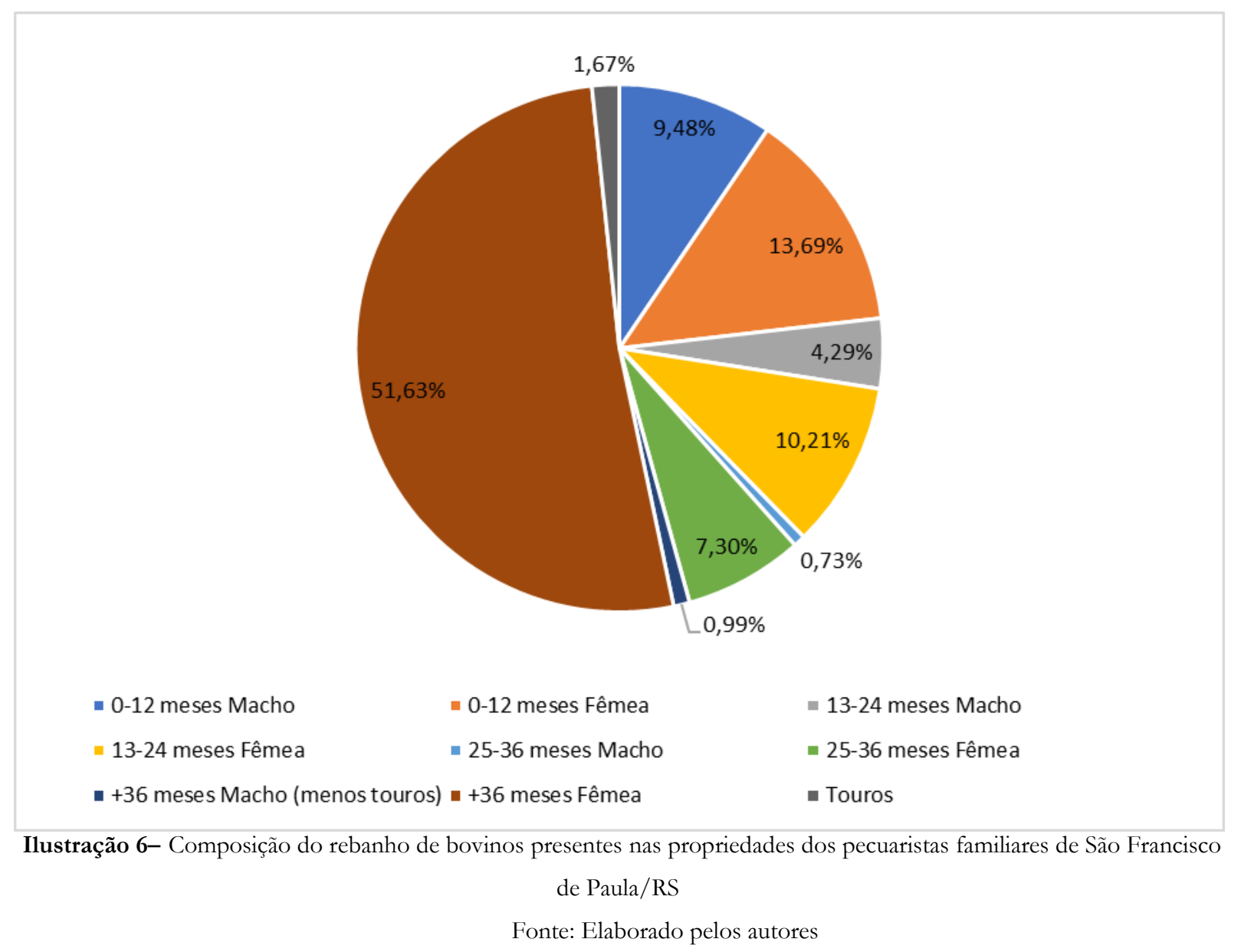

Outro dado extraído da Ilustração 6 que chama atenção é a baixa relação touro:vaca, que fica em 1,67\%, uma vez que o ideal é de 3 a 4\%, dependendo do manejo de monta utilizado na propriedade. A baixa fecundidade fica evidenciada nos dados da EMATER/RS (2017) quanto aos índices de nascimento, que atualmente estão em $45 \%$.

O rebanho de machos nas propriedades de entrevistados não supera $8 \%$, demonstrando a aptidão das propriedades à cria e não ao ciclo completo, recria ou engorda. Como as áreas são relativamente pequenas e o fluxo de comercialização da recria e engorda é menor, a atividade de cria é preferida pelos entrevistados. 


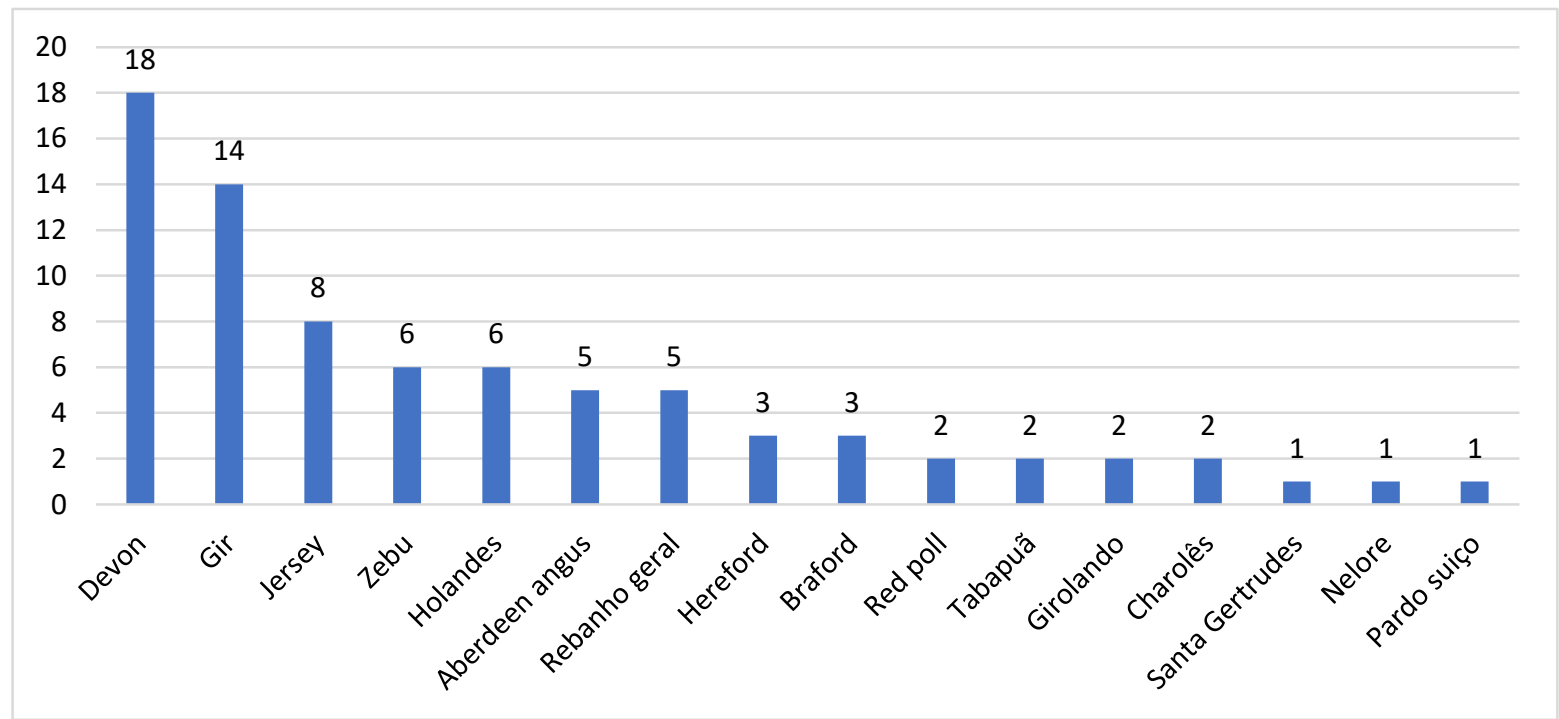

Ilustração 7- Raças de bovinos citadas pelos pecuaristas familiares de São Francisco de Paula/RS

Fonte: Elaborado pelos autores

Em suas respostas em relação à raça utilizada na propriedade (Ilustração 7), os 36 entrevistados citaram 15 raças diferentes, mais cinco de rebanho geral sem caracteristicas fenotípicas raciais de determinada raça, sendo esses oriundos de animais cruzados com zebuinos. Chama atenção que as citações de raças criadas nas propriedades foram de 79, dando em média 2,19 raças diferentes por prorpiedade, caracterizando animais cruzados com caracteristicas fenotípicas mais próxima da raça citada.

O cruzamento entre raças fica evidenciado no momento em que sete produtores citaram uma raça definida na propriedade, sendo destas seis com aptidão a corte e uma com aptidão leiteira. Ou seja, os outros 29 utilizam mais de uma raça bovina em sua propriedade. 


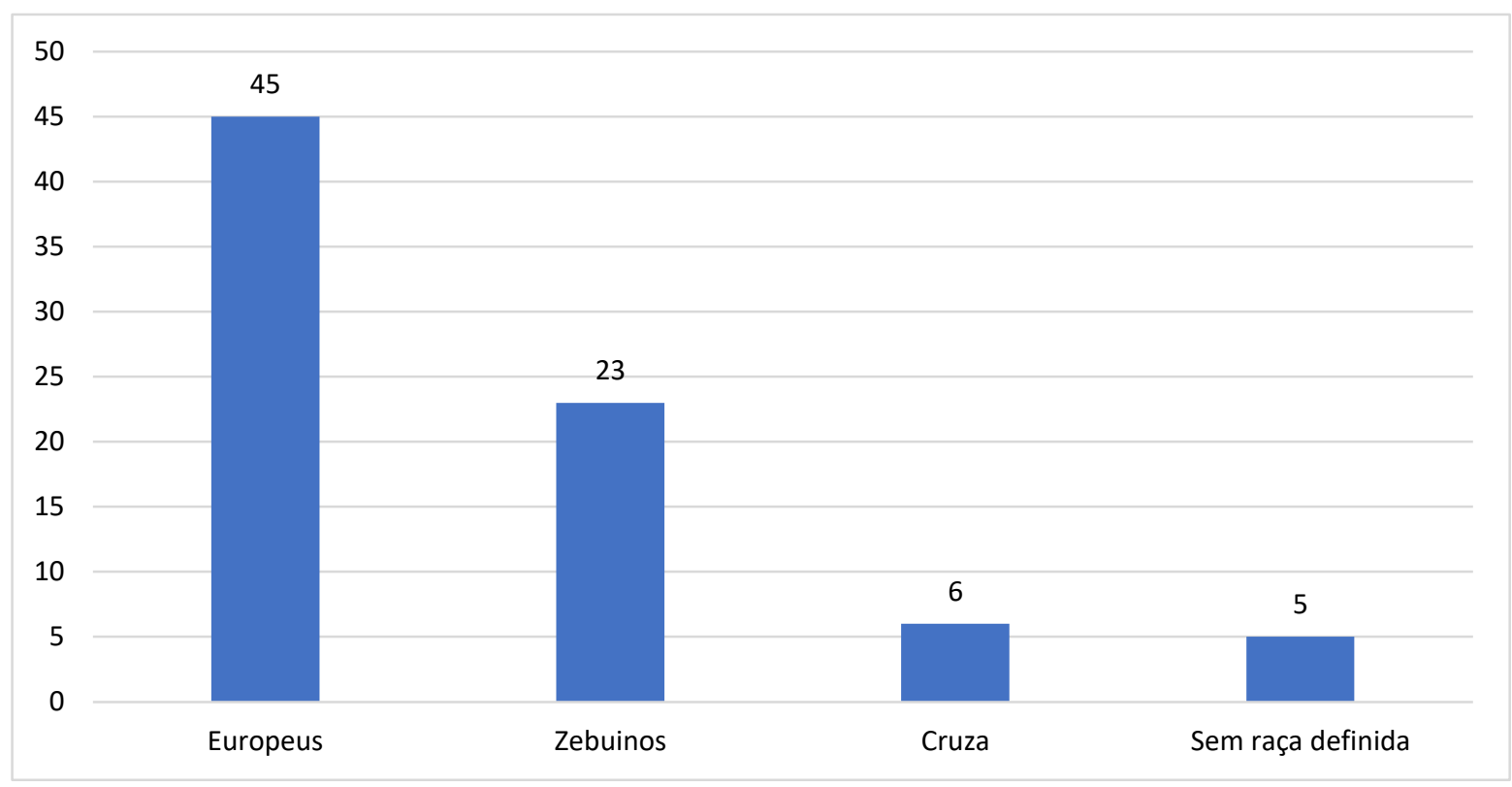

Ilustração 8- Grupos raciais de bovinos citados pelos pecuaristas familiares de São Francisco de Paula/RS Fonte: Elaborado pelos autores

Segundo Ries, Luz e Araújo (2012), as raças mais frequentemente utilizadas pelos produtores de queijo dos Campos de Cima da Serra, variam entre Gir e Guzerá como zebuínas e Devon como raça europeia. Segundo os mesmos, a introdução de linhagens leiteiras nas propriedades seria para viabilizar a produção do queijo também no inverno, mas não especializando demais ao leite para não se perder a rusticidade típica dos animais de corte.

As raças europeias se destacam nas citações da Ilustração 8, porém é predominante as mais diversas cruzas entre estas. Apesar da predominância destas, o sangue zebuíno é utilizado na maioria dos cruzamentos para agregar rusticidade, principalmente pela menor susceptibilidade aos carrapatos, parasita de grande importância tanto no município quanto no estado do Rio Grande do Sul, e com capacidade para suportar de certa forma o déficit alimentar que ocorre no período invernal.

A composição da renda familiar foi realizada junto aos produtores através de estimativa e importância da categoria da renda para os entrevistados. 


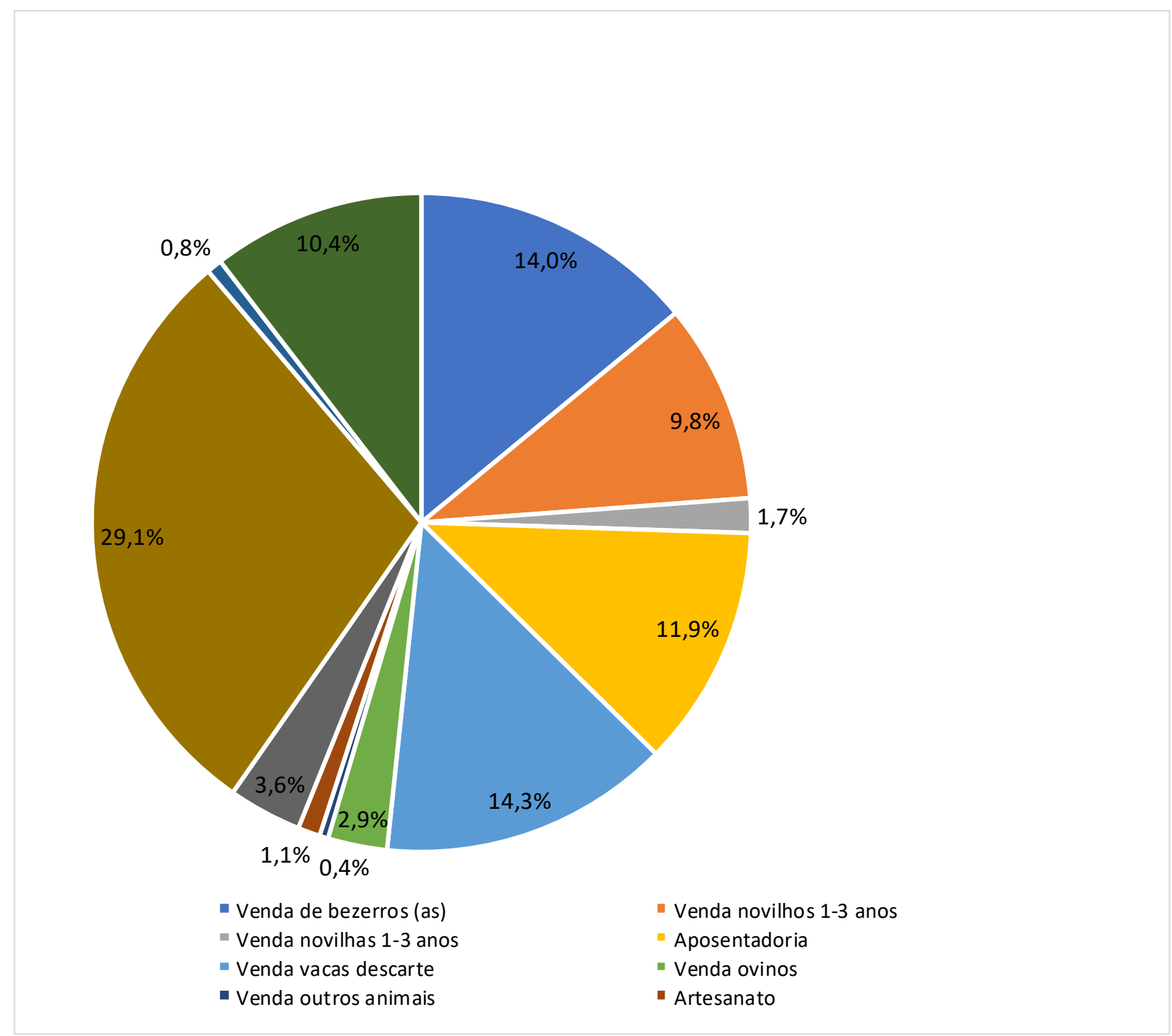

Ilustração 9- Estratificação da importância de cada atividade dentro das propriedades da pecuária familiar Fonte: Elaborado pelos autores

Deve-se destacar a importância do queijo artesanal serrano na composição da renda das propriedades dos entrevistados, característica esta peculiar aos Campos de Cima da Serra, em geral, onde a tradição do queijo serrano vem de muitos anos. Ries, Luz e Araújo (2012) citam que o queijo serrano pode compor até $50 \%$ da renda bruta anual para propriedades de até 200 ha, concordando com o encontrado na pesquisa deste.

A venda de terneiros e vacas de descarte, estas últimas gordas ou magras, também compõem parte fundamental da renda destes pecuaristas. Estas que são os principais meios de desfrute do rebanho bovino, são, quando somadas (28,3\%), praticamente semelhantes à renda provinda do queijo artesanal serrano $(29,1 \%)$, porém, como a venda de animais é uma fonte de renda sazonal (apenas na safra) o queijo é considerado fator de sustentabilidade da propriedade, enquanto a venda de bovinos configura o "lucro". 
Destaca-se também a importância da aposentadoria, citada por 14 pecuaristas, do total de 34 que responderam esta questão. Esta fica colocada como a quarta renda mais importante dos entrevistados. Quando analisada apenas entre os que a citaram como fonte de renda, esta representa $28 \%$ da composição da renda dos produtores, número próximo aos $30,8 \%$ dos pecuaristas familiares com idade acima dos 60 anos citados na Tabela 2.

Quanto às principais dificuldades identificadas, essas foram consideradas complexas para os produtores rurais, pois o constante problema citado era em relação à infraestrutura rodoviária. Então estes foram induzidos a informar outras dificuldades, e mesmo assim foi predominante o apontamento sobre infraestrutura rodoviária.

A segurança, tanto relacionada aos produtos de origem animal, quanto à segurança pessoal das famílias foi bastante citada. O abigeato é corriqueiro e representa grande entrave a pecuária regional.

A qualidade da energia elétrica que chega à propriedade também foi citada como uma das dificuldades, justificado as redes elétricas monofásicas inadequadas, dificultando o uso de motores de ordenhadeiras e moedores, entre outros equipamentos elétricos.

As altas despesas envolvendo a atividade pecuária, e a baixa margem de lucro também foram citadas entre os entrevistados. Entre estes custos, foram colocados como os mais importantes os insumos agropecuários (adubos, medicamentos e agrotóxicos), os custos com a legalização da sapeca do campo nativo (que demanda projeto com responsável técnico) e mão-deobra que além de escassa tem alto valor.

Dificuldade relatada também entre os pecuaristas familiares foi o acesso a saúde, pois muitos destes estão mais próximos ao município de Caxias do Sul do que ao de São Francisco de Paula, e com isso têm extremas dificuldades de serem atendidos lá. Isso porque a Coordenadoria Regional de Saúde (CRS) dos assistidos por São Francisco de Paula é a $1^{\text {a }}$ CRS e a dos assistidos por Caxias do Sul é a $5^{a}$ CRS e estes não podem ser assistidos em saúde por coordenarias diferentes, necessitando deslocar-se até a sede de São Francisco de Paula, o que os onera e muitos acabam postergando atendimentos simples na rede de saúde.

\section{CONSIDERAÇÕES FINAIS}

Como um público definido, o pecuarista familiar já é algo peculiar, se isolarmos ele em uma região como a dos Campos de Cima da Serra ele se destaca com características ainda mais definidas. 
Exímios criadores, produtores de um dos mais antigos queijos do Brasil, os serranos são proprietários de cultura e "saber fazer" únicos, que apesar de estarem adaptados ao clima e às intemperes da região, também se mostram susceptíveis. A pressão de atividades mais rentáveis do que a pecuária é grande, porém todas com altos riscos envolvidos. Um fato que comprova a estabilidade da atividade é que existem muitos entre os pecuaristas familiares entrevistados com idade avançada, pois é uma atividade segura e que sustentou muitas famílias com o suor da lida na pecuária.

Tornar as propriedades mais eficientes, rentáveis e sustentáveis demanda mão de obra ou sucessão, o que em ritmo lento vem sendo feito. Uma opção interessante seria a formalização da produção do queijo serrano para agregar valor a este produto que é bastante procurado.

Algo que é inerente ao trabalho do produtor rural, mas que influência muito na sua vida é a infraestrutura de estradas. Este é o maior anseio dos entrevistados quando se questiona as dificuldades da atividade.

A manutenção desta categoria social é fundamental caso a preocupação com a preservação ambiental da região seja relevante. Dando-lhes infraestrutura e permitindo um uso sustentável das propriedades, estes serão os maiores cuidadores do meio ambiente. Com mínimas alterações e manejo mínimo, estes mantêm as paisagens intactas, proporcionando a manutenção de um ecossistema único no país.

\section{REFERÊNCIAS}

AMBROSINI, Larissa Bueno; MIGUEL, Louvis de Andrade; FILIIPPI, Eduardo Ernesto Evolução e diferenciação dos sistemas agrários nos Campos de Cima da Serra: origem dos pecuaristas familiares produtores do Queijo Serrano. Desenvolvimento e Meio Ambiente, v. 26, p.171-187, dez. 2012. Disponível em: https://revistas.ufpr.br/made/article/view/26460/19678

BÚRIGO, Fábio Luiz; CAZELLA, Ademir Antonio; ROVER, Oscar José (Coord.). Análise socioeconômica e ambiental de Porto União (SC): um estudo a partir da disciplina Vivência em Agricultura Familiar. Florianópolis: UFSC, 2015. (Retratos da agricultura familiar, 2).

COTRIM, Marcelo Souza. Pecuária Familiar na região da serra do sudeste do Rio Grande do Sul: Um estudo sobre a origem e a situação socioagroeconômica do Pecuarista Familiar no município de Canguçu/RS. 2003. 142 f. Dissertação (Mestrado) - Curso de Desenvolvimento Rural, Universidade Federal do Rio Grande do Sul, Porto Alegre, 2003. Cap. 030.

EMATER/RS - ASCAR. EMPESA DE ASSISTÊNCIA TÉCNICA E EXTENSÃO RURAL. Acervo interno - dados estatísticos relacionados aos pecuaristas familiares. Escritório municipal de São Francisco de Paula. 2017.

GIL, A. C. Métodos e técnicas de pesquisa social. 5ª EDIÇÃO. São Paulo: Atlas, 199. 206 p. 
Diagnóstico socioeconômico de pecuaristas familiares de São Francisco de Paula

IBGE - INSTITUTO BRASILEIRO DE GEOGRAFIA E ESTATÍSTICA. Censo Demográfico 2010. 2010. Brasil Disponível em: http://cod.ibge.gov.br/2WUU0. Acesso em: 09 jul. 2017.

PORTO, Rafael Gastal; BEZERRA, Antônio Jorge Amaral Caracterização da Pecuária Familiar na Região da Campanha Meridional: Estudo de Caso no Município de Bagé-RS. Revista Brasileira de Agrociências, v.15, n.1-4, p.101-107, 2009.

RIBEIRO, Cláudio Marques. Estudo do Modo de Vida dos Pecuaristas Familiares da Região da Campanha do Rio Grande do Sul. 2009. 303 f. Tese (Doutorado em Desenvolvimento Rural) - Faculdade de Ciências Econômicas da Universidade Federal do Rio Grande do Sul, Porto Alegre, 2009.

RIES, Jaime Eduardo; LUZ, João Carlos Santos da; ARAÚJO, Saionara. Projeto de qualificação e certificação do queijo serrano produzido nos Campos de Cima da Serra do Rio Grande do Sul relato parcial da experiência. Agroecologia e Desenvolvimento Rural Sustentável, Porto Alegre, v. 5, n. 1, p.10-19, jan. 2012. Disponível em: http://www.emater.tche.br/site/arquivos_pdf/teses/Rev-Agr_02-Rel-Exp.pdf . Acesso em: 29 mar. 2018

RIO GRANDE DO SUL. Lei $\mathbf{n}^{\mathbf{0}}$ 13.515, de 13 de setembro de 2010. Institui o Programa Estadual de Desenvolvimento da Pecuária de Corte Familiar e dá outras providências. Disponível em: http://www.al.rs.gov.br/filerepository/repLegis/arquivos/13.515.pdf . Acesso em: $20 / 11 / 2017$.

RIO GRANDE DO SUL. Rebanho bovino do município de São Francisco de Paula no ano de 2016. Inspetoria Veterinária. São Francisco de Paula, RS.

WAQUIL, Paulo Dabdab; MATE Alessandro; NESKE, Márcio Zamboni; BORBA, Marcos Flávio Silva. (Org.). Pecuária familiar no Rio Grande do Sul: História, diversidade social e dinâmicas de desenvolvimento. Porto Alegre, Rio Grande do Sul: Editora Ufrgs, 2016. 290 p.

Recebido em: 26/11/2018

Aceito em: 05/07/2019 
ANEXO 1 - Modelo de questionário aplicado aos entrevistados

Diagnóstico sócio-econômico em Pecuária Familiar no município de São Francisco de Paula

I - IDENTIFICAÇÃO DO ESTABELECIMENTO:

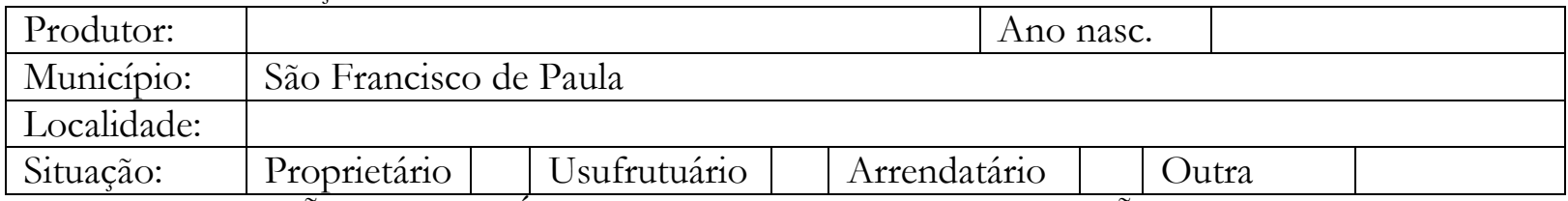

II - COMPOSIÇÃO DA FAMÍLIA E DISPONIBILIDADE DE MÃO-DE-OBRA:

\begin{tabular}{|l|l|l|l|l|}
\hline Nome & $\begin{array}{c}\text { Ano } \\
\text { nasc. }\end{array}$ & Parentesco & $\begin{array}{c}\text { Residência na } \\
\text { propriedade } \\
(\mathrm{S} / \mathrm{N})\end{array}$ & $\begin{array}{c}\text { Grau de } \\
\text { instrução }\end{array}$ \\
\hline 1. & & & & \\
\hline 2. & & & & \\
\hline 3. & & & & \\
\hline 4. & & & & \\
\hline 5. & & & & \\
\hline
\end{tabular}

GRAU DE INSTRUÇÃO - fundamental incompleto, fundamental completo, Ensino médio completo ou incompleto, Ensino Técnico, Superior incompleto, Superior completo, Pósgraduação.

III - OCUPAÇÃO DA ÁREA:

\begin{tabular}{|l|l|l|l|}
\hline \multicolumn{1}{|c|}{ Ocupação } & \multicolumn{1}{c|}{ Área (ha $)$} & \multicolumn{1}{c|}{ Ocupação } & \multicolumn{1}{c|}{ Área (ha ) } \\
\hline Total & & Lavouras anuais $^{1}$ & \\
\hline Benfeitorias & & Lavouras perenes $^{2}$ & \\
\hline Campo nativo & $\begin{array}{l}\text { Pastagem de } \\
\text { inverno }^{3}\end{array}$ & \\
\hline Matas nativas & & Pastagem de verão $^{4}$ & \\
\hline Florestamento & & Campo melhorado $^{5}$ & \\
\hline
\end{tabular}

Florestamento - Pinus; Eucalipto outros

\begin{tabular}{|c|c|c|c|}
\hline \multicolumn{4}{|l|}{1 - Espécies cultivadas: } \\
\hline \multicolumn{4}{|l|}{${ }^{2}$ - Espécies cultivadas: } \\
\hline \multicolumn{4}{|l|}{${ }^{3}$ - Espécies cultivadas: } \\
\hline \multicolumn{4}{|l|}{${ }^{4}$ - Espécies cultivadas: } \\
\hline \multicolumn{4}{|l|}{ 5-Espécies cultivadas: } \\
\hline $\begin{array}{l}\mathrm{N}^{\circ} \text { divisões no campo } \\
\text { nativo: }\end{array}$ & $\begin{array}{l}\text { Sistema de } \\
\text { pastoreio: }\end{array}$ & Contínuo & Rotativo \\
\hline $\mathrm{N}^{\circ}$ divisões nas pastagens: & $\begin{array}{l}\text { Sistema de } \\
\text { pastoreio: }\end{array}$ & Contínuo & Rotativo \\
\hline Campo nativo & Suplementação & Mineral & $\begin{array}{l}\text { Proteica ou } \\
\text { energética }\end{array}$ \\
\hline Pastagem cultivada & Suplementação & Mineral & $\begin{array}{l}\text { Proteica ou } \\
\text { energética }\end{array}$ \\
\hline
\end{tabular}

IV - INSTALAÇÕES DISPONÍVEIS

\begin{tabular}{|c|c|c|c|c|c|}
\hline Tipo & $(\mathrm{S} / \mathrm{N})$ & $\begin{array}{c}\text { Estado } \\
\text { (Bom, Regular, } \\
\text { Ruim) }\end{array}$ & Tipo & $(\mathrm{S} / \mathrm{N})$ & $\begin{array}{c}\text { Estado } \\
\text { (Bom, Regular, } \\
\text { Ruim) }\end{array}$ \\
\hline
\end{tabular}




\begin{tabular}{|c|c|c|c|c|c|c|}
\hline \multicolumn{2}{|l|}{ Galpão } & & & Bretes & & \\
\hline \multicolumn{2}{|l|}{ Mangueiras } & & & Balanças & & \\
\hline \multicolumn{2}{|l|}{ Cerca fixa } & & & Cerca elétrica & & \\
\hline \multicolumn{2}{|c|}{$\begin{array}{l}\text { Banheiro } \\
\text { Imersão/aspersão }\end{array}$} & & & & & \\
\hline \multicolumn{7}{|c|}{$\begin{array}{l}\text { Existe um planejamento para manutenção ou construção de instalações para os próximos } 5 \text { anos? } \\
\text { Caso sim, quais? }\end{array}$} \\
\hline \multicolumn{7}{|c|}{ V - MÁQUINAS E IMPLEMENTOS DISPONÍVEIS } \\
\hline Tipo & $(\mathrm{S} / \mathrm{N})$ & & $\begin{array}{l}\text { Estado } \\
\text { m, Regular, } \\
\text { Ruim) }\end{array}$ & Tipo & $(\mathrm{S} / \mathrm{N})$ & $\begin{array}{c}\text { Estado } \\
\text { (Bom, Regular, } \\
\text { Ruim) }\end{array}$ \\
\hline Trator & & & & Roçadeira & & \\
\hline Arado & & & & Plantadeira & & \\
\hline Colheitadeira & & & & Outros quais & & \\
\hline \multicolumn{7}{|c|}{ VI - REBANHO BOVINO: } \\
\hline \multicolumn{3}{|c|}{ Categoria } & Número (Cab.) & \multicolumn{2}{|c|}{ Categoria } & Número (Cab.) \\
\hline \multicolumn{3}{|l|}{ Vacas de cria } & & \multicolumn{2}{|c|}{ Novilhas 1 a 2 anos } & \\
\hline \multicolumn{3}{|c|}{ Vacas de descarte } & & \multicolumn{2}{|c|}{ Novilhas 2 a 3 anos } & \\
\hline \multicolumn{3}{|l|}{ Touros } & & \multicolumn{2}{|c|}{ Novilhas + de 3 anos } & \\
\hline \multirow{2}{*}{\multicolumn{3}{|c|}{$\begin{array}{l}\text { Bezerras/Terneiras (até } 1 \text { ano) } \\
\text { Bezerros/Terneiros (até } 1 \text { ano) }\end{array}$}} & & \multicolumn{2}{|c|}{ Novilhos 1 a 2 anos } & \\
\hline & & & & \multicolumn{2}{|c|}{ Novilhos 2 a 3 anos } & \\
\hline \multicolumn{3}{|c|}{$\begin{array}{l}\text { Bezerros/Terneiros (até } 1 \text { ano) } \\
\text { Vacas de leite }\end{array}$} & & Novilhos $+\mathrm{d}$ & anos & \\
\hline
\end{tabular}

VII - OUTROS ANIMAIS:

\begin{tabular}{|l|l|l|l|}
\hline \multicolumn{1}{|c|}{ Espécie/Categoria } & Número (Cab.) & \multicolumn{1}{c|}{ Espécie/Categoria } & Número (Cab.) \\
\hline Ovelhas & & Cavalos & \\
\hline Carneiros & & Porcos & \\
\hline Cordeiros (as) & & Galinhas & \\
\hline Borregos (as) & & Outras & \\
\hline
\end{tabular}

VIII - MANEJO REPRODUTIVO BOVINO:

\begin{tabular}{|l|l|l|l|l|l|}
\hline $\begin{array}{l}\text { Sistema de } \\
\text { acasalamento: }\end{array}$ & $\begin{array}{l}\text { Monta } \\
\text { Natural }\end{array}$ & $\begin{array}{l}\text { Inseminação } \\
\text { Artificial }\end{array}$ & IATF $^{1}$ & \\
\hline $\begin{array}{l}\text { Época de } \\
\text { acasalamento: }\end{array}$ & & & \\
\hline $\begin{array}{l}\text { Raças ou Cruzamentos } \\
\text { Utilizados: }\end{array}$ & Peso no desmame: & & \\
\hline $\begin{array}{l}\text { Época de desmame dos } \\
\text { terneiros: }\end{array}$ & & \\
\hline Sistema de desmame dos terneiros: & \\
\hline $\begin{array}{l}\text { Critérios p/ definição da época } \\
\text { e sistema de desmame: }\end{array}$
\end{tabular}

1 - IATF - Inseminação artificial em tempo fixo

IX - MANEJO REPRODUTIVO OVINO:

\begin{tabular}{|c|c|}
\hline Época de acasalamento: & \\
\hline Raças ou Cruzamentos Utilizados: & \\
\hline Época de desmame dos cordeiros: & Peso no desmame: \\
\hline Sistema de desmame dos cordeiros & \\
\hline
\end{tabular}

Extensio: R. Eletr. de Extensão, ISSN 1807-0221 Florianópolis, v. 16, n. 33, p. 35-56, 2019. 
Critérios p/ definição da época e sistema

de desmame:

X - COMPOSIÇÃO PERCENTUAL DA RENDA DA PROPRIEDADE (no último ano):

\begin{tabular}{|l|l|l|l|l|l|}
\hline \multicolumn{1}{|c|}{ Renda } & $\%$ & \multicolumn{1}{|c|}{ Renda } & $\%$ & \multicolumn{1}{|c|}{ Renda } & $\%$ \\
\hline Venda de terneiros(as) & & Venda de vacas descarte & & Venda de leite & \\
\hline Venda novilhos (1 a 3 anos) & & Venda de ovinos & & Venda de queijo & \\
\hline Venda novilhas (1 a 3 anos) & & Venda de outros animais & & Venda de mão-de-obra & \\
\hline Aposentadoria & & Artesanato & & Outras rendas & \\
\hline Observações & \multicolumn{2}{l}{} \\
\hline
\end{tabular}

XI - PRINCIPAIS DIFICULDADES IDENTIFICADAS PELA FAMÍLIA:

XII - OBSERVAÇÕES DO TÉCNICO: 